\title{
Our Song: Evaluating the Effect of Music during the Pre-class Period on Stu- dent Achievements of Learning Objectives
}

\section{Dr. Angel Ari Perez-Mejia, Quinnipiac University}

Ari Perez-Mejia earned his undergraduate degree in civil engineering at the Universidad Tecnologica Centroamericana (UNITEC) in Honduras, and did his graduate work at the University of South Carolina. He received his $\mathrm{PhD}$ in 2014 and joined the engineering faculty at Quinnipiac University that same year. His interests are in the conservation of archaeological sites and in engineering education.

\section{Dr. John E. Greenleaf P.E., Quinnipiac University}

John Greenleaf received his Ph.D. from Lehigh University in 2007 and is a licensed professional engineer. In 2013 he joined the faculty of Quinnipiac University to lead the development of a new Civil Engineering program within a newly established engineering school. His professional background includes work in environmental engineering, construction, and undergraduate engineering education.

\section{Dr. Priscilla C Fonseca P.E., Quinnipiac University}

Priscilla Fonseca is an assistant professor of civil engineering at Quinnipiac University. Prior to joining Quinnipiac, Dr. Fonseca was a research associate and teaching fellow at Princeton University. She also has structural engineering experience in industry and she is licensed as a professional engineer. She holds a PhD from Northwestern University, an MSE from University of Michigan, and an SB from MIT, all in civil engineering.

\section{Dr. Chris Hakala, Quinnipiac University}

Chris Hakala is the director of university teaching and learning at qunnipiac university. Chris has a Ph.D. In experimental psychology and has been a faculty member and administrator in various colleges and universities for almost 20 years. His research interests include memory, language and the teaching/learning process. 


\title{
Our Song: Evaluating the Effect of Music during the Pre-class Period on Student Achievements of Learning Objectives
}

\begin{abstract}
:
The moments prior to the start of class provide many opportunities for engaging with students in a less formal setting. These moments can be used to establish a pre-class environment conducive to student motivation, focus, confidence, and ultimately the achievement of learning objectives. For example, the pre-class environment could include informal conversations between the students and instructor. These conversations can help the students develop rapport with the instructor, while giving the instructor an opportunity to evaluate student perceptions about course difficulty or workload. The pre-class environment could also be non-conversational. For example, playing music that is topically related to the class subject (e.g. playing "Good Vibrations" before delivering a lecture on mechanical vibrations) may increase motivation, focus attention, or generate excitement. As instructors will often have a preferred pre-class environment, there is a large amount of anecdotal evidence regarding its effect on student attitudes. However, there is little published material discussing on the impact (if any) of the pre-class environment on student learning objectives. This study uses a multi-dimensional experimental model to measure the impact of the pre-class environment on both student attitudes and learning objectives. Three different pre-class environments are tested: 1) informal conversations, 2) topical music, and 3) no activity. The influence of other variables such as gender, year, and major are also examined.

Recommendations to enhance both are given based on the findings. Given the potential benefit, this work also examines some of the practical aspects of pre-class activities, including instructor preferences and the transition to regular class time.
\end{abstract}

\section{Background:}

The effects of music on cognitive abilities have been a topic of discussion since Rauscher et al. ${ }^{1}$ published an article detailing the "Mozart Effect". In their study, a group of undergraduates were administered a spatial abilities test after listening to a Mozart piece or sitting in silence while listening to relaxation instructions. The students that had been exposed to the music performed much better as compared to students in the control group. This was widely reported in the media, and led to a frenzy of activity in the media and social policy spheres, including the project to distribute a Mozart cd to every baby born in Georgia ${ }^{2}$. Subsequently, Davies 3 reported a host of other academic benefits to music listening such as "music in the classroom reduces stress, increases productivity, regulates energy, and creates a relaxed supportive learning environment". Davies also recommended playing songs with lyrics related to the subject being studied, as it led to establishing an enhanced learning atmosphere. Davies included a list of songs arranged by subject that could be used to teach specific subjects due to lyrical connection. However, Davies was writing with a view on K-12 education and so it is unclear how translatable her results are to undergraduate instruction. However, other studies ${ }^{4}$ have been unable to find similar beneficial results of music listening on cognitive performance. 
The reason for the discrepancy between results may be understood by a new take on the Rauscher et al. results. Chabris et al. ${ }^{5}$ performed a meta-analysis on the data available and found evidence that the purported 'Mozart effect' may instead be replicated through other non-musical activities which the subjects enjoyed. This seems to indicate that the improved cognitive abilities are caused by changes in mood and arousal in the students, a hypothesis first formulated by Thompson et al. ${ }^{6}$. Under this hypothesis, the short term gains in cognitive abilities after musical listening were caused by a student's positive reaction to upbeat tempo music, which improved their mood and increased their attention. A similar improvement could be achieved by a non-musical activity that the students enjoyed, while a sad song would not show the improvement in performance. Schellenberg ${ }^{2}$ presents data supporting these conclusions; and Hallam et al. ${ }^{7}$ found similar results when studying the effects of background music on primary school students' performance (aged 10 to 12). While background music did improve performance in arithmetic and memory tasks, the selection of music also played an important role; music could either stimulate or calm the students. Appropriate selection of music was then necessary to reap the full academic benefits. Hallam et al. conclude that "appropriately selected music could be used to create an optimum environment for children to undertake individual work". However, this study was also performed in a K-12 environment so its applicability to undergraduate instruction is unclear.

Whereas the direct effect of music on learning outcomes is not clear, it may be an effective tool to increase rapport between student and instructor. The establishment and continuation of student-teacher rapport is an essential part of improving the classroom environment ${ }^{8}$. Because musical tastes are non-threatening information for the students to share, while at the same time often feeling like essential parts of our personality; a shared musical connection may significantly impact a student's perception of their instructor, and provide discussion material to reinforce rapport throughout the semester.

Lastly, music can also help foster creative engineers by establishing a learning environment where creativity is seen as a desirable trait ${ }^{9}$. Zhou states that creativity is an essential skill for engineers to possess, as it allows for unexpected connections and solutions to problems. In order to foster creativity, he recommends to "build a creative learning environment in the classroom and a creative learning culture in institutions". The repeated playing of music, an eminently creative endeavor, can convey the importance of creativity through ubiquity.

This study looks at music and its use during the time period just prior to the start of class. The effect of the time spent prior to the start of a delivery period (hereafter called the pre-class period) is not well understood. Perhaps tellingly, the authors were unable to determine a widely accepted name in the literature for this period of class time. The dearth of literature also extended to finding the impact of activities undertaken during this period on the achievement of learning objectives. However, anecdotal evidence is widely available as most instructors have preferences in terms of how to spend this time.

Commonly, instructor preferences will favor spending time chatting with student on a oneon- one basis, both to informally assess how the learning process is taking place and to build rapport. Other common activities include setting up the classroom, discussing with the classroom as a whole, or playing music both to create a positive learning environment and to create a clear delineation between the pre-class period and the delivery period. 
Because the pre-class period offers additional contact time between student and instructor, determining whether it can be used to improve the students' learning experience presents a tantalizing opportunity. As instructors seek to maximize the effectiveness of their teaching, time constraints are often the principal deterrent to adding non-engineering components (such as creative elements) to their teaching style. The pre-class period offers untapped potential, and due to its informal nature can be used for a wide range of activities.

The influence of classroom environment and instructor-teacher rapport on student attitudes is a topic that has been well researched. Much of this earlier work has produced either mixed results when examining student performance, or has focused on more anecdotal evidence such as student preferences. However, little information is available in the open literature related to how the classroom environment affects student learning outcomes specifically. Although an increase in rapport due to the effect of music may tangentially affect student learning, in this paper, the authors attempt to develop a systematic framework for directly evaluating the effect of pre-class activities on learning outcome achievements.

\section{Methods:}

The class examined was an introductory 3 credit hour engineering course. It is required for every student with a declared major in engineering (Civil, Industrial, Mechanical, and Software) or an undeclared general engineering major. However, the class is open to all majors and some non-engineering students are also present. Although it is designed to be taken during the freshman year, which many students do, this course may be taken at any point in the student's career. The engineering program is a new addition to this institution, and as such this class is unique in the larger institutional context due to its subject and its focus on hand on activities. The university is a medium sized, private institution with a student population drawn mainly from surrounding areas. As the institution is mostly focused on liberal arts, there exists a larger educational infrastructure for the humanities and social sciences. However, the addition of the 4 offered engineering majors represent the largest commitment to STEM.

The class is similar to many other introductory engineering courses and meant to provide a fun, low stakes introduction to engineering and to each of the four engineering disciplines. This is accomplished by alternating general engineering lectures with discipline-specific modules. Each module is 5 lectures long, including an introductory lecture delivered at the beginning of the semester (all introductory lectures occur over 4 consecutive delivery periods). The students have one principal instructor, who delivers the general engineering material, and are taught by guest instructors for the discipline specific lessons.

Each discipline specific project is carefully chosen to provide both a fun, hands on activity/project which is representative of the discipline, but also to introduce important concepts within that discipline. Students are evaluated primarily through the projects, with secondary evaluation coming from scaffolding activities for the project. There are no tests administered throughout the course, which reinforces the low stakes atmosphere desired. However, this results in the discipline specific projects having a significant impact on student assessments, as they account for $74 \%$ of the course grade. Because of the high point value of 
these assignments, it is necessary that the engineering concepts required for the completion of the assignment be well understood by the students.

Student enrolment (survey population) was eighty four (84) students distributed between four sections. Although divided into four discipline-specific modules, testing only occurred during the civil engineering module. All students participated in every module regardless of discipline preference. Table 1 shows the distribution of students among majors. The course was composed primarily of freshman (71/84) but also contained sophomores, juniors and seniors (numbering 9, 3, 1 respectively). The course gender composition was $18 \%$ female and $82 \%$ male. For the Civil Engineering module where this survey was conducted, the four sections divided evenly between two Civil Engineering faculty members. The students had no previous exposure to these faculty in the form of an engineering course. Class sections occurred at different times throughout the day: 9:30 am (20 students), 11:00 am (21 students), 2:00 pm (21 students) and 3:30 pm (22 students).

Table 1: Introductory engineering course composition by major.

\begin{tabular}{|l|l|l|}
\hline Major & $\begin{array}{l}\text { Number (out of 84 } \\
\text { total students) }\end{array}$ & $\begin{array}{l}\text { Percent } \\
\text { Composition }\end{array}$ \\
\hline Civil Engineering (CE) & 15 & $17.9 \%$ \\
\hline Industrial Engineering (IE) & 5 & $6.0 \%$ \\
\hline Mechanical Engineering (ME) & 21 & $25.0 \%$ \\
\hline Software Engineering (SE) & 9 & $10.7 \%$ \\
\hline Undecided Engineering (UE) & 21 & $25.0 \%$ \\
\hline Computer Science (CS) & 2 & $2.4 \%$ \\
\hline None of the Above/ Non-Engineering (UE) & 11 & $13.1 \%$ \\
\hline
\end{tabular}

Apart from the instructors and students, the principle experimental variable was the pre-class atmosphere created by each individual instructor. Three basic conditions were created in the 10 minute pre-class time period: 1) Simple 1-to-1 or small group conversations between the instructor and students in the class 2) Topical music played for all students with no instructor interaction and 3) No instructor interaction or music prior to class. Although topical music was found without much difficulty for the material delivered in this class, repeated use of topical music may present difficulties when finding connections to class material. While a personal musical knowledge and internet searches may facilitate finding topically related music, repetition and tangential connections may be necessary in a longer class. This preclass environment was varied across both lectures and instructors; Table 2 shows the distribution of study activities across the various lectures and sections.

Table 2: Distribution of experimental conditions across 3 lectures with 4 sections each. Key: T: verbal (talking) interaction with faculty; M: topical music and no verbal interaction; N: No faculty-student interaction or music.

\begin{tabular}{|l|l|l|l|l|}
\hline Class/Survey & $\begin{array}{l}\text { Instructor } \\
\text { A (Sec. 1) }\end{array}$ & $\begin{array}{l}\text { Instructor } \\
\mathrm{A} \text { (Sec. 2) }\end{array}$ & $\begin{array}{l}\text { Instructor } \\
\mathrm{B} \text { (Sec. 3) }\end{array}$ & $\begin{array}{l}\text { Instructor } \\
\mathrm{B} \text { (Sec. 4) }\end{array}$ \\
\hline Lecture 1 & $\mathrm{M}$ & $\mathrm{N}$ & $\mathrm{T}$ & $\mathrm{N}$ \\
\hline Lecture 2 & $\mathrm{N}$ & $\mathrm{M}$ & $\mathrm{M}$ & $\mathrm{T}$ \\
\hline Lecture 3 & $\mathrm{T}$ & $\mathrm{T}$ & $\mathrm{N}$ & $\mathrm{M}$ \\
\hline
\end{tabular}


The lectures focused on a 3-week hands on project which provided context for the introductory topics discussed. The project was the design, assembly, and testing of a 34" tall pasta tower constructed out of pasta (Fettuccini). The towers were then subjected to various loadings in the form of both a water tank $\left(2 \mathrm{qt}-1 \mathrm{ft}^{3}\right)$ and a simulated earthquake using of a commercially available small-scale shake table (model: Quanser Shake Table II).

In all classes, learning objectives for a particular class were articulated at the beginning of class in both oral and written forms. This format consisted of a listing of lesson objectives on the chalkboard prior to the commencement of class. All lesson objectives were consistent between sections and the coordinated lecture material addressed every objective. Students were then surveyed in writing at the end of class in order to determine their attainment of the enumerated objectives. The wording of the assessment was identical to that of the previously listed learning objectives and thus identical for all sections. Table 3 summarizes the learning objectives covered during the 3 lectures (these are also the survey questions utilized for the study).

Table 3: Learning objectives stated for each survey given.

\begin{tabular}{|c|c|c|c|c|c|}
\hline Survey & $\begin{array}{l}\text { Learning } \\
\text { Objective \#1 }\end{array}$ & $\begin{array}{l}\text { Learning } \\
\text { Objective \#1 }\end{array}$ & $\begin{array}{l}\text { Learning } \\
\text { Objective \#1 }\end{array}$ & $\begin{array}{l}\text { Learning } \\
\text { Objective \#1 }\end{array}$ & $\begin{array}{l}\text { Learning } \\
\text { Objective \#1 }\end{array}$ \\
\hline Lecture 1 & $\begin{array}{l}\text { Give examples of } \\
\text { dead and live } \\
\text { loads carried by } \\
\text { structures. }\end{array}$ & $\begin{array}{l}\text { Define stress, } \\
\text { strain, and the } \\
\text { elastic modulus. }\end{array}$ & $\begin{array}{l}\text { List two key } \\
\text { characteristics of a } \\
\text { truss. }\end{array}$ & $\begin{array}{l}\text { Differentiate } \\
\text { between the basic } \\
\text { modes of } \\
\text { structural failure. }\end{array}$ & $\begin{array}{l}\text { Given the } \\
\text { material and } \\
\text { geometric } \\
\text { properties of } \\
\text { fettuccine, } \\
\text { compute the } \\
\text { allowable tensile } \\
\text { and compressive } \\
\text { forces carried by } \\
\text { a single strand. }\end{array}$ \\
\hline Lecture 2 & $\begin{array}{l}\text { List the purpose } \\
\text { of building a } \\
\text { water storage } \\
\text { tank. }\end{array}$ & $\begin{array}{l}\text { Describe the } \\
\text { relationship } \\
\text { between pressure } \\
\text { and height of a } \\
\text { column of liquid. }\end{array}$ & $\begin{array}{l}\text { Calculate the } \\
\text { height necessary } \\
\text { to generate a water } \\
\text { pressure of } 130 \\
\text { psi. }\end{array}$ & $\begin{array}{l}\text { Sketch a } \\
\text { preliminary } \\
\text { design for a pasta } \\
\text { tower that } \\
\text { includes all } \\
\text { necessary } \\
\text { elements for the } \\
\text { construction of } \\
\text { the water tower. }\end{array}$ & N/A \\
\hline Lecture 3 & $\begin{array}{l}\text { Describe how a } \\
\text { shake table } \\
\text { models } \\
\text { earthquakes. }\end{array}$ & $\begin{array}{l}\text { Sketch an } \\
\text { updated design } \\
\text { for the pasta } \\
\text { tower talking } \\
\text { into account any } \\
\text { testing results. }\end{array}$ & N/A & N/A & N/A \\
\hline
\end{tabular}

Note: N/A indicates no additional learning objectives were given.

Students were given approximately 10 minutes to complete the survey. Only surveys completed as given during the time assigned in lecture were considered; no make-up surveys were given. The survey was presented as a low-risk assessment; students were given full credit for completing the survey and their grade was not adversely impacted by incorrect answers. Surveys were collected by each lecturer. Following collection, names were redacted from the surveys and each student was assigned a random identification number. 
Identification numbers were consistent across all three surveys so anonymous individuals could be tracked. The surveys were then provided to two individuals not associated with the course material for the purposes of evaluation regarding this work.

Assessment and evaluation of the surveys was performed using a rubric which was identical across all surveys and sections. The rubric was developed by the two non-teaching evaluators who were provided with the learning objectives (questions). Ten random quiz samples were taken from each survey in order to gauge the appropriateness of the rubrics and the consistency of grading between the two individuals. Once finalized, the rubric was applied by both evaluators to every student in the sample for all three surveys. Figure 1 shows a skeleton form of the rubric used for evaluation. Paper scores were compiled electronically for all rubrics; no data was discarded at this point in the study.

Rubric scores were grouped according to section (1-4). Individual question scores and total (cumulative) survey scores for each of the four sections were compiled. Analysis of Variance (ANOVA) and multi-variable analysis of Variance (MANOVA) was used to examine the mixed effects of section, quiz and condition (Music, Talking, or No Interaction). Interaction between the effects was also studied.

Student Lesson Objective Rubric

Course: XXX 110

Assignment:

Semester: Fall 2014

Student \#:

Reviewer:

Date:

\begin{tabular}{|l|l|l|l|l}
\hline & Unsatisfactory 1 & Developing 2 & Satisfactory 3 & Exemplary 4 \\
\hline Objective & $\begin{array}{l}\text { Student shows no } \\
\text { ability/interest in } \\
\text { achieving this skill }\end{array}$ & $\begin{array}{l}\text { Student shows signs they } \\
\text { are developing the skills we } \\
\text { require }\end{array}$ & $\begin{array}{l}\text { Student meets what } \\
\text { we determine to be a } \\
\text { minimum stand ard }\end{array}$ & $\begin{array}{l}\text { Student Shows they } \\
\text { have this skill beyond } \\
\text { our minimum } \\
\text { threshold }\end{array}$ \\
\hline $\begin{array}{l}\text { List objective/ } \\
\text { question \# } \\
\text { here (1-5) }\end{array}$ & $\begin{array}{l}\text { Student cannot } \\
\text { answer the question } \\
\text { in any part, } \\
\text { misunderstands } \\
\text { question, or provides } \\
\text { a random guess that } \\
\text { is in no part correct. }\end{array}$ & $\begin{array}{l}\text { Student provides a } \\
\text { significantly incomplete or } \\
\text { incorrect answer (<50\% } \\
\text { correct). Several parts } \\
\text { terminglogy/nomenclature } \\
\text { used. }\end{array}$ & $\begin{array}{l}\text { Student provides a } \\
\text { substantially correct } \\
\text { answer (>50\% } \\
\text { correct). Answer may } \\
\text { miss some details or } \\
\text { use incorrect } \\
\text { terminology. }\end{array}$ & $\begin{array}{l}\text { Student can provide a } \\
\text { correct and well- } \\
\text { detailed answer using } \\
\text { the terminology/ } \\
\text { nomenclature } \\
\text { demonstrated in class. }\end{array}$ \\
\hline 1 & & & & \\
\hline 2 & & & & \\
\hline 3 & & & & \\
\hline 4 & & & & \\
\hline 5 & & & & \\
\hline
\end{tabular}

Figure 1: Rubric used to assess learning objectives for every survey considered in this study.

\section{Results and Discussion:}

The results of this data analysis fail to show any interaction between the various experimental conditions created during the pre-class atmosphere. Additionally, there was no statistical significance seen regarding other variables such as sex, year, and major. For all tests, F $<1.0$ and $\mathrm{p}>0.05$ indicating no statistical significance. Although, no significant interaction was established, this study does not rule out the possibility that the pre-class atmosphere and 
rapport building impact the achievement of learning objectives. Several possible reasons exist for these findings, all of which should be taken into account during future studies.

First, the pre-class atmosphere, although important, represents only a small fraction of the total class time (in this case 10 minutes out of 1.5 hours). Additionally, the pre-class activity and the learning objective assessment were conducted at opposite ends of the class. As a result, the pre-class environment may contribute only marginally towards the total rapportbuilding process. It may be useful to identify other similar rapport-building activities that occur over the entirety of the class.

Second, it is possible that some activities that build rapport for one instructor may be counterproductive for another instructor. An example of the former in the context of this study would be playing music. The instructor's choice or personal preference in regard to music may not align with the preferences of the students, thus proving counterproductive in terms of rapport building. The same can be said for conversation; for one instructor, conversation and small talk may come naturally, while for another this may be awkward and difficult thus hurting rapport. It would be helpful to understand the impact of any activity in terms of whether or not it was successful in rapport-building prior to the assessment of learning objectives.

Lastly, it may be that the overall effect of rapport building contributes little towards the student's ability to meet the classroom learning objectives or that the short nature of the module did not allow sufficient time for rapport building. Other factors including instructional delivery (skill of instructor, type of lecture, etc), environmental conditions (time of day), and student capacity may in this instance play a much more significant role in the achievement of learning objectives.

It should be noted, however, that significant differences were seen in terms of the individual learning objectives and to what extent they were successfully achieved. These differences should be expected as learning objectives may vary in terms of how they are addressed pedagogically by the instructor, the cognitive level required for their successful achievement, and the manner in which they are assessed. It is also possible that the pre-class atmosphere may contribute in different ways depending on each situation. For example, music may work well to engage students for a hands-on pedagogical approach, while it may be counterproductive for other activities that may be more reflective in nature.

Although the results of this study were inconclusive, the effects of music on learning is an area that should be researched further. The abundance of anecdotal evidence from instructors indicate that it is a topic of interest among the educational community. The effects of preclass activities may be elucidated by following the framework presented this study with a larger sample size and detailed observation of pre-class activities. These observations should seek to further categorize the presented options (i.e. what type of music specifically was played, whether the instructor-student chatting was natural or forced). It is also possible that the effects of music on learning are not scalable, and can only be appreciated in a specific class size. Future research should strive to evaluate both smaller and larger class sizes. 


\section{Conclusions/Recommendations:}

This study looked at the influence of pre-class activities and rapport building on the student's ability to meet learning objectives. Based on additional student data, it also examined the influence of other variables such as gender, year, and major. Following statistical analysis of the data using ANOVA and MANOVA, it was determined that there is no significant difference when comparing the different pre-class formats. This conclusion was drawn using scores for both individual learning objectives and overall survey scores (cumulative score for one test). Additionally, is there no significant interaction of any of the collected variables (including sex, year in school, and major).

While rapport building is an important aspect of the student-teacher relationship, and may influence student perceptions, it is not clear that it has a significant impact on the achievement of learning objectives. It is possible that due to the limited sample size and experimental scope, subtle differences and influences may have been overlooked. It should be noted however, that there was significant difference in learning objective achievement across all sections. This result indicates that other factors such as instructional delivery, instructor personality, time of day, and student composition may play a much more significant role.

This study contributes to the understanding of rapport and student learning by investigating a possible connection between the two during the pre-class time period. Although no connection could be established based on this study's data, it does not conclusively rule-out the possibility of a connection. This line of investigation and the experimental procedures utilized do provide a foundation for future work in an area that has experienced little investigation or discussion within the open literature.

\section{References:}

${ }^{1}$ Rauscher, F. H., Shaw, G. L., \& Ky, K. N. (1993). Music and spatial task performance. Nature, 365, 611.

${ }^{2}$ Schellenberg, E. G. (2005). Music and Cognitive Abilities. Psychological Science, 14(6), 317-320.

${ }^{3}$ Davies, M. A. (2000). Learning ... the Beat Goes on. Childhood Education, 76(3), 148-153.

${ }^{4}$ Jäncke, L., \& Sandmann, P. (2010). Music listening while you learn: no influence of background music on verbal learning. Behavioral and Brain Functions : BBF, 6, 3.

${ }^{5}$ Chabris, C. F., Steele, K. M., Dalla Bella, S., Peretz, I., Dunlop, T., Dawe, L. A., ... Rauscher, F. H. (1999).

Prelude or requiem for the "Mozart Effect"? Nature, 400, 826-828. 
${ }^{6}$ Thompson, W. F., Schellenberg, E. G., \& Husain, G. (2001). Arousal, mood and the Mozart effect.

Psychological Science, 12, 248-251.

${ }^{7}$ Hallam, S., Price, J., \& Katsarou, G. (2002). The effects of background music on primary school pupils' task performance. Educational Studies, 28(2), 111-122.

${ }^{8}$ Finelli, C., Klinger, A., \& Budny, D. (2001). Strategies for Improving the Classroom Environment. Journal of Engineering Education, 90(4), 491-497.

${ }^{9}$ Zhou, C. (2012). Fostering creative engineers: a key to face the complexity of engineering practice. European Journal of Engineering Education, 37(January 2015), 343-353. 